\title{
Age-Related True Exfoliation of the Lens Capsule: Phacoemulsification Surgery Results
}

\author{
Alex Lap Ki Nga Marcus M. Marcet ${ }^{\mathrm{a}} \quad$ Jimmy S.M. Lai ${ }^{\mathrm{a}}$ \\ Jane C.C. Yeung ${ }^{\text {b, } c}$ \\ a Department of Ophthalmology, LKS Faculty of Medicine, The University of Hong Kong, \\ ${ }^{b}$ Department of Ophthalmology, Queen Mary Hospital, and ${ }^{C}$ Premier Medical Centre, \\ Hong Kong, SAR, China
}

\section{Key Words}

True exfoliation · Lens · Cataract $\cdot$ Phacoemulsification

\begin{abstract}
Historically associated with glassblowers, true exfoliation of the crystalline lens involves a splitting or delamination of the capsule. We reviewed the phacoemulsification records of a single surgeon for patients with true exfoliation of the lens capsule. The incidence in our series was $2.2 \%$ ( 6 in 278 cases). The average age was 85.0 years. All patients had successful phacoemulsification outcomes, which may have been due to accurate recognition of the condition and appropriate surgical planning. Our findings support the notion that true exfoliation may be more often associated with advanced age rather than infrared radiation.
\end{abstract}

\author{
2015 The Author(s) \\ Published by S. Karger AG, Basel
}

\section{Introduction}

True exfoliation of the crystalline lens involves a splitting or delamination of the capsule. Historically, the entity has also been referred to as glassblower's cataract due to the known risk of prolonged exposure to heat and infrared radiation causing the condition [1]. Other ocular conditions associated with true exfoliation include age, trauma, uveitis and glaucoma $[2,3]$. Awareness of the link between advanced age and true exfoliation of the lens capsule has grown. For example, using transmission electron microscopy, one study found agerelated ultrastructural changes in a patient with true exfoliation of the lens capsule [4].

\begin{tabular}{ll}
\hline KARGER 125/\% & $\begin{array}{l}\text { Dr. Jane C.C. Yeung } \\
\text { 8F, Block S Queen Mary Hospital } \\
\text { 102 Pokfulam Road Man } \\
\text { Hong Kong, SAR (China) } \\
\text { E-Mail yeung.jane@gmail.com }\end{array}$
\end{tabular}


$\mathrm{Ng}$ et al.: Age-Related True Exfoliation of the Lens Capsule: Phacoemulsification Surgery Results

In this case series, we report 6 patients who underwent phacoemulsification with true exfoliation of the lens capsule. We recognized the true exfoliation either preoperatively with a rolled up and/or split anterior capsule or intraoperatively by the double-ring sign [1]. All cases were performed under local anesthesia by the same surgeon (J.C.C.Y.) over a 6-month period, out of a total of 278 cases performed during the same period.

\section{Case Presentations}

The clinical characteristics of the 6 patients are summarized in table 1 . The average age of our series was $85.0 \pm 7.1$ years (range: 72-92). None of the patients had a history of prolonged infrared radiation or heat exposure, trauma or ocular inflammation. In 3 patients (cases 1, 5, 6), the clinical diagnosis of true exfoliation was made preoperatively by slit-lamp examination (fig. 1). The anterior capsules were sent for histological confirmation in cases 1 and 6 (fig. 2). In the other 3 patients (cases 2,3,4), the condition was only recognized intraoperatively, and we did not arrange for histological examination of the capsulorhexis specimen (fig. 3). In 2 patients (cases 1 and 5), the fellow eye was pseudophakic with previous cataract operation done elsewhere, thus we could not ascertain if true exfoliation was present. Of the other 4 patients, true exfoliation of the lens capsule was present bilaterally in 1 patient (case 6) and in only one eye of the other 3 patients.

\section{Case 1}

An 89-year-old female with no prior ophthalmic history presented with cataracts. Preoperatively, a delaminated anterior capsule floating in the anterior chamber was seen on slit-lamp biomicroscopy (fig. 1a), and the edge of delamination could be seen on retroillumination (fig. 1b). She underwent phacoemulsification, which required Tryptan blue (Vision Blue, 0.1\%; DORC International BV, Zuidland, The Netherlands) staining of the capsule. Histology of the anterior capsule revealed areas of focal splitting (fig. 2a).

\section{Case 2}

The second patient was also an 89-year-old female. Preoperatively, she had old corneal scars, but the patient denied any history of ocular trauma or inflammation, and no specific cause of the corneal scars could be identified. The delaminated anterior lens capsule was noticed intraoperatively. Phacoemulsification was performed uneventfully without the need for capsular stains. Postoperatively, she was noted to have progressive increase in the cupdisc ratio but a normal intraocular pressure. She was subsequently diagnosed with normal tension glaucoma.

\section{Case 3}

An 85-year-old male presented with good past ophthalmic history. A partially delaminated anterior lens capsule was found intraoperatively. He had uneventful phacoemulsification without the need of capsular staining.

\section{Case 4}

A 72-year-old male had a bi-temporal hemianopia due to a pituitary macroadenoma. His history was otherwise unremarkable. He underwent uneventful phacoemulsification without needing any capsular staining. 
$\mathrm{Ng}$ et al.: Age-Related True Exfoliation of the Lens Capsule: Phacoemulsification Surgery Results

\section{Case 5}

An 83-year-old female presented with cataracts. Several years before, she had an acute angle-closure attack and had undergone laser iridotomy. Her intraocular pressure was normal since the angle-closure episode and did not require glaucoma medication. A delaminated anterior lens capsule was diagnosed preoperatively. She underwent uneventful phacoemulsification. Adequate visualization of the lens capsule required capsular stain. Figure 3 shows the double-ring sign, which was noted intraoperatively.

Case 6

A 92-year-old male with no prior ophthalmic history presented with a dense cataract. Delaminated anterior lens capsules were found in both eyes. Uneventful phacoemulsification was performed. Histology of the anterior capsule confirmed the diagnosis of true exfoliation (fig. 2b).

\section{Discussion}

We report on a series of patients of advanced age with true exfoliation of the lens capsule. The incidence in our single-surgeon single-center series was $2.2 \%$ ( 6 in 278 cases). To determine the true incidence of this rare condition would require a large, prospective study over a longer timeframe. The condition was consistent with an age-related etiology, as no other causes, such as a history of occupational exposure to prolonged heat or infrared radiation, were identified. Age-related degeneration of the lens epithelial cells could comprise the integrity of the lens capsule, causing vesicles to form. When the vesicles coalesce to form larger vacuoles, delamination of the anterior portion of the capsule may occur, which results in true exfoliation [4-6]. Wong et al. [2] recently reported a series of Chinese patients with a similar age-related pattern of true exfoliation. The authors also reported an association of the condition with glaucoma, with $29.2 \%$ of cases having preexisting chronic glaucoma and $20.8 \%$ with a prior history of laser iridotomy. In our series, 1 patient (case 5) had a history of acute angle closure with subsequent laser iridotomy performed.

Generally, one would expect bilateral occurrence in an age-related condition. Of the 4 patients with a phakic fellow eye, one had bilateral involvement while the other 3 had unilateral involvement. However, the possibility of asymmetry between the eyes exists. To exclude the possibility of subclinical involvement in the fellow eye, the lens capsule could be sent for histological examination in future cataract surgery. The remaining 2 patients had pseudophakic fellow eyes at the time of presentation; thus, in these cases the possibility of true exfoliation in the fellow eye could not be determined.

The average age of our series was 85.0 years, which was among the oldest reported in the literature. The reported age of true exfoliation ranged from 80.5 to 85.4 years [2, 7-9]. Cashwell et al. [7] reported 11 cases of presumed age-related true exfoliation cases with the highest average age of 85.4 years. With regard to the geographical distribution of true exfoliation, authors have reported case series from different continents, including Asia, North America and Europe. The relatively small number of patients reported in the literature precludes meaningful analysis of the role that geography may play in the development of true exfoliation.

In our series, the diagnosis of true exfoliation was made by recognizing the double-ring sign and/or the presence of a split or rolled-up anterior capsule, which was strongly associated with true exfoliation [1, 5, 6, 9-11]. In 2 patients from our series, the anterior capsule had histological confirmation of the true exfoliation syndrome, with delamination and rolling 
$\mathrm{Ng}$ et al.: Age-Related True Exfoliation of the Lens Capsule: Phacoemulsification Surgery Results

up of the anterior capsule. The double-ring sign was due to partial splitting of the anterior capsule, where two complete continuous curvilinear capsulorhexis (CCC) procedures may be required in a single operation to achieve complete capsulorhexis [8]. Ataka et al. [5] demonstrated on electron microscopy that the anterior lens capsule in cases with the double-ring sign had horizontal splits in the anterior capsule, with concomitant abnormal epithelial changes including vacuole-like spaces and widened intercellular spaces, which supported the relation with true exfoliation.

The presence of true exfoliation of the lens capsule typically increases the risk of capsule complications such as radial extension and radial tear $[9,11,12]$. In our case series, all cases of age-related true exfoliation syndrome had a good outcome from phacoemulsification and capsular implantation of the intraocular lens. Kulkarni et al. [13] reported good safety outcomes from phacoemulsification in 5 cases with true exfoliation due to a history of prolonged heat exposure. Wong et al. [2] also noted good outcomes in their series. In all of our patients, the CCC was successfully performed, although in 2 cases capsular staining with Tryptan blue dye was required. The dye helped ensure the CCC was of full thickness instead of partial thickness.

We believe recognizing the true exfoliation, either preoperatively (splitting of the anterior capsule on slit-lamp biomicroscopy) or intraoperatively (double-ring sign), was the key to our good surgical outcome without any capsular complications. To detect true exfoliation syndrome preoperatively, image modalities such as the Pentacam or anterior-segment optical coherence tomography may also be employed $[6,14,15]$. To our knowledge, our series composed age-related true exfoliation cases with one of the oldest average ages reported. All cases demonstrated a good surgical outcome due to prompt recognition of the condition.

\section{Statement of Ethics}

The patients signed an informed consent before the surgery.

\section{Disclosure Statement}

The authors have no financial or proprietary conflicts of interest concerning the materials discussed in this article.

\section{References}

1 Braude LS, Edward DP: Partial splitting of the anterior lens capsule giving a 'double-ring' sign. Arch Ophthalmol 1995;113:705-708.

2 Wong AL, Chan TC, Fong AH, Lam BN, Yuen HK: Clinical characteristics and surgical outcomes of phacoemulsification in true exfoliation syndrome. J Cataract Refract Surg 2014;40:82-86.

3 Yamamoto N, Miyagawa A: True exfoliation of the lens capsule following uveitis. Graefes Arch Klin Exp Ophthalmol 2000;238:1009-1010.

4 Shentu XC, Zhu YN, Gao YH, Zhao SJ, Tang YL: Electron microscopic investigation of anterior lens capsule in an individual with true exfoliation. Int J Ophthalmol 2013;6:553-556.

5 Ataka S, Kohno T, Kurita K, Wada S, Takahashi Y, Shiraki K: Histopathological study of the anterior lens capsule with a double-ring sign. Graefes Arch Klin Exp Ophthalmol 2004;242:245-249.

6 Cooke CA, Lum DJ, Wheeldon CE, Teoh H, McGhee CN: Surgical approach, histopathology, and pathogenesis in cataract associated with true lens exfoliation. J Cataract Refract Surg 2007;33:735-738.

-7 Cashwell LF Jr, Holleman IL, Weaver RG, van Rens GH: Idiopathic true exfoliation of the lens capsule. Ophthalmology 1989;96:348-351. 
$\mathrm{Ng}$ et al.: Age-Related True Exfoliation of the Lens Capsule: Phacoemulsification Surgery Results

-8 Kumari R, Tadros A: Double complete capsulorhexis required for cataract extraction: is it a sign of true exfoliation? Int Ophthalmol 2013;33:285-287.

9 Yamamoto Y, Nakakuki T, Nishino K, Yagyu K, Kishi S, Ueno H, et al: Histological and clinical study of eyes with true exfoliation and a double-ring sign on the anterior lens capsule. Can J Ophthalmol 2009;44:657662.

10 Wollensak G, Wollensak J: Double contour of the lens capsule edges after continuous curvilinear capsulorhexis. Graefes Arch Clin Exp Ophthalmol 1997;235:204-207.

11 Abe T, Hirata H, Hayasaka S: Double-ring and double-layer sign of the anterior lens capsule during cataract surgery. Jpn J Ophthalmol 2001;45:657-658.

$\checkmark 12$ Kim KH, Chung ES, Chung TY: Radial extension of capsulorhexis in true exfoliation patient: a potentially hazardous complication. J Cataract Refract Surg 2009;35:590-592.

$\checkmark 13$ Kulkarni AR, Al-Ibrahim J, Haider S, Elsherbiny S, Scott R: Phacoemulsification in true exfoliation of the lens capsule: a case series. Eye (Lond) 2007;21:835-837.

14 Chamney SM, Hughes ME, Sinton JE: The use of Pentacam in the assessment of true exfoliation of the lens capsule. Eur J Ophthalmol 2015;25:e50-e52.

15 Tan DK, Aung T, Perera SA: Novel method of assessing delamination of the anterior lens capsule using spectral-domain optical coherence tomography. Clin Ophthalmol 2012;6:945-948.

Table 1. Clinical characteristics of 6 patients with true lens exfoliation

\begin{tabular}{|c|c|c|c|c|c|c|c|c|c|c|c|}
\hline Case & $\begin{array}{l}\text { Age, } \\
\text { years }\end{array}$ & Sex & $\begin{array}{l}\text { OD/ } \\
\text { OS }\end{array}$ & Medical history & $\begin{array}{l}\text { Cataract } \\
\text { grading }\end{array}$ & $\begin{array}{l}\text { Fellow eye lens } \\
\text { status }\end{array}$ & Past ocular history & $\begin{array}{l}\text { Preop. } \\
\text { VA }\end{array}$ & $\begin{array}{l}\text { Postop. } \\
\text { VA }\end{array}$ & $\begin{array}{l}\text { Time of dia- } \\
\text { gnosis of true } \\
\text { exfoliation }\end{array}$ & $\begin{array}{l}\text { Intraoperative } \\
\text { complications } \\
\text { and remarks }\end{array}$ \\
\hline 1 & 89 & $\mathrm{~F}$ & os & $\begin{array}{l}\text { Hypertension, atrial } \\
\text { fibrillation }\end{array}$ & $\mathrm{NS}+\mathrm{CC}++$ & Pseudophakic & Nil & 0.3 & 0.7 & $\begin{array}{l}\text { Preoperative } \\
\text { Confirmed on } \\
\text { histology }\end{array}$ & $\begin{array}{l}\text { Nil } \\
\text { Vision blue- } \\
\text { aided capsu- } \\
\text { lorhexis }\end{array}$ \\
\hline 2 & 89 & $\mathrm{~F}$ & os & Hypertension & $\mathrm{NS}++\mathrm{CC}++$ & $\begin{array}{l}\text { No lens } \\
\text { exfoliation }\end{array}$ & $\begin{array}{l}\text { Faint corneal scars (denies history } \\
\text { of trauma) } \\
\text { Normal tension glaucoma } \\
\text { diagnosed after cataract surgery }\end{array}$ & 0.2 & 0.5 & Intraoperative & Nil \\
\hline 3 & 85 & M & OD & $\begin{array}{l}\text { Hypertension, gout, } \\
\text { ischemic heart disease, } \\
\text { hyperlipidemia }\end{array}$ & $\mathrm{NS}++\mathrm{CC}++$ & $\begin{array}{l}\text { No lens } \\
\text { exfoliation }\end{array}$ & Nil & 0.3 & 0.6 & Intraoperative & Nil \\
\hline 4 & 72 & M & os & $\begin{array}{l}\text { Hypertension, } \\
\text { hyperlipidemia }\end{array}$ & NS++ & $\begin{array}{l}\text { No lens } \\
\text { exfoliation }\end{array}$ & $\begin{array}{l}\text { Bi-temporal visual field defect due } \\
\text { to pituitary macroadenoma }\end{array}$ & 0.1 & 0.7 & Intraoperative & Nil \\
\hline 5 & 83 & $\mathrm{~F}$ & os & $\begin{array}{l}\text { Breast carcinoma (in } \\
\text { remission) }\end{array}$ & $\mathrm{NS}++\mathrm{CC}++$ & Pseudophakic & $\begin{array}{l}\text { History of acute angle closure with } \\
\text { laser peripheral iridotomy per- } \\
\text { formed. Normal intraocular pressure }\end{array}$ & 0.2 & 0.7 & Preoperative & $\begin{array}{l}\text { Nil } \\
\text { Vision blue- } \\
\text { aided capsu- } \\
\text { lorhexis }\end{array}$ \\
\hline 6 & 92 & M & os & Hypertension & NS+++-PSC++ & True exfoliation & Nil & 0.03 & 0.7 & $\begin{array}{l}\text { Preoperative } \\
\text { Confirmed on } \\
\text { histology }\end{array}$ & Nil \\
\hline
\end{tabular}

NS = Nuclear sclerosis; CC = cortical cataract; PSC = posterior subcapsular cataract. $\mathrm{VA}=$ Visual acuity, in Snellen decimal notation; Preop. $=$ preoperative; Postop. = postoperative. 
Case Reports in

Ophthalmology

\begin{tabular}{l|l}
\hline Case Rep Ophthalmol 2015;6:401-407 \\
\hline DOI: 10.1159/000442345 & $\begin{array}{l}\text { (c) 2015 The Author(s). Published by S. Karger AG, Basel } \\
\text { www.karger.com/cop }\end{array}$ \\
\hline
\end{tabular}

$\mathrm{Ng}$ et al.: Age-Related True Exfoliation of the Lens Capsule: Phacoemulsification Surgery Results
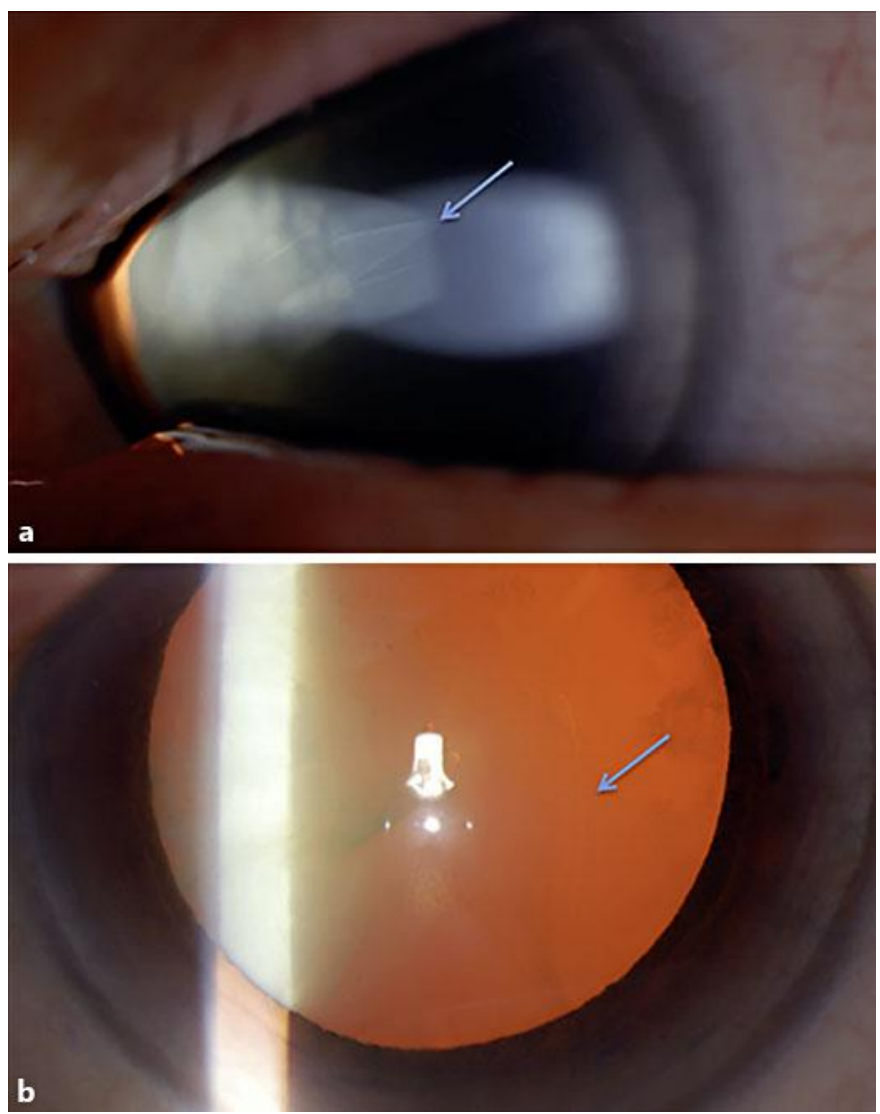

Fig. 1. a Slit-lamp biomicroscopic image showing a delaminated anterior lens capsule (arrow) floating in the anterior chamber. $\mathbf{b}$ The edge of delamination (arrow) as seen on retroillumination. 


\section{Case Reports in \\ Ophthalmology}

\begin{tabular}{l|l}
\hline Case Rep Ophthalmol 2015;6:401-407 \\
\hline DOI: 10.1159/000442345 & $\begin{array}{l}\text { @ } 2015 \text { The Author(s). Published by S. Karger AG, Basel } \\
\text { www.karger.com/cop }\end{array}$ \\
\hline
\end{tabular}

Ng et al.: Age-Related True Exfoliation of the Lens Capsule: Phacoemulsification Surgery Results

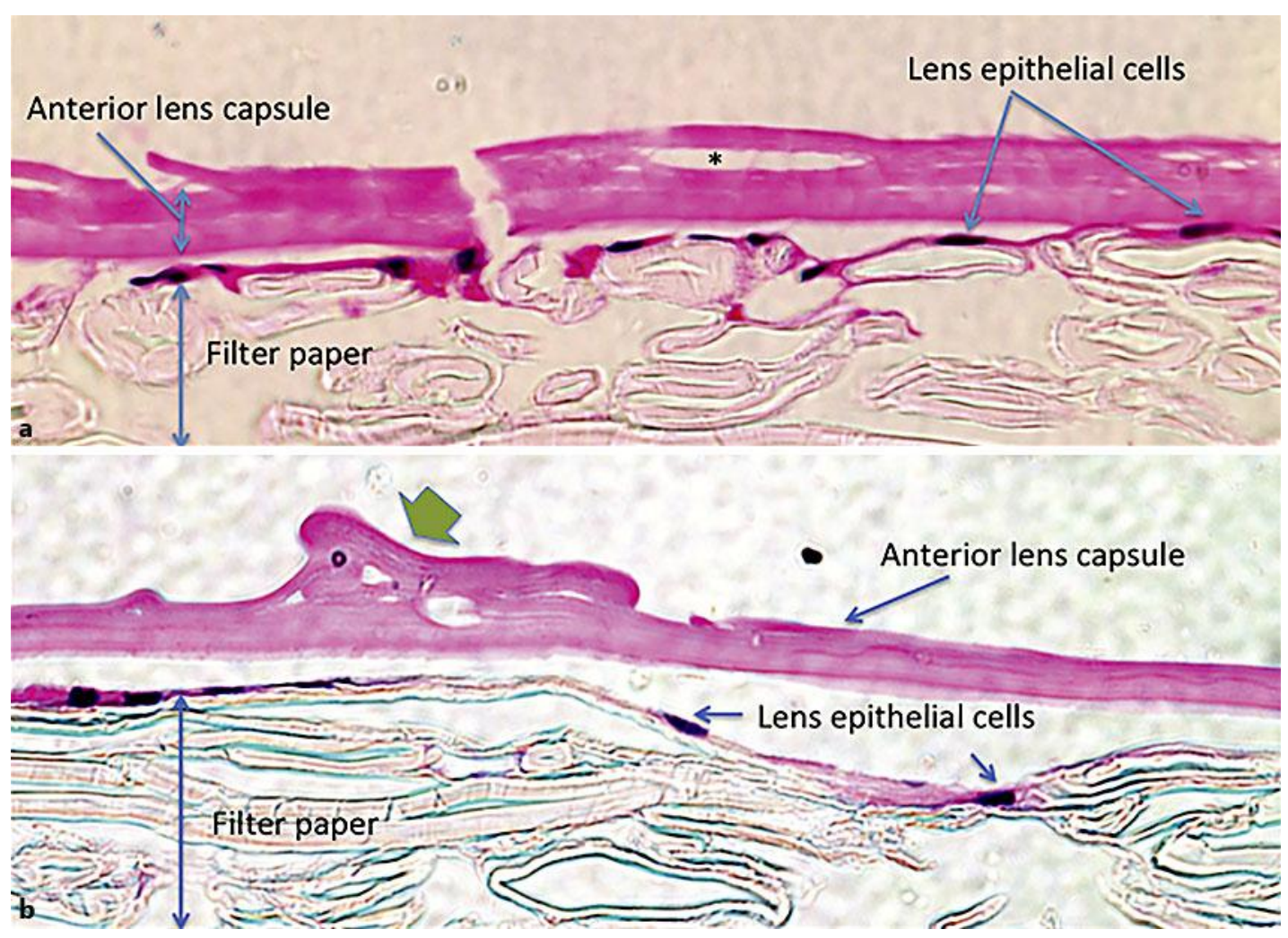

Fig. 2. Photomicrographs of true exfoliation of the anterior lens capsule from the capsulorhexis during phacoemulsification surgery. In both images, normal lens epithelial cells appear along the posterior surface of the anterior lens capsule. Filter paper was used to obtain a flat mount of the lens capsule. a Lamellar splitting along the anterior lens capsule is seen (HE. $\times 40$ ). b A scroll of the anterior lens capsule is shown (green arrow; HE. ×20).

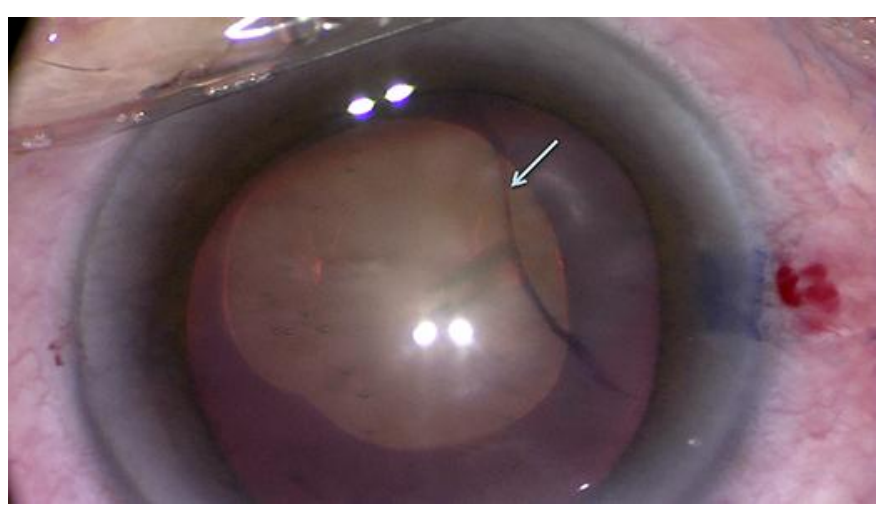

Fig. 3. Intraoperative image showing the double-ring sign in case 5. After completion of the capsulorhexis aided by Tryptan blue stain, the double-ring sign (arrow) was noted with another layer of anterior capsule remaining. A second capsulorhexis procedure was required. 